\title{
GEOGRAFIA HISTÓRICA - CONSIDERAÇÕES
}

\author{
RUI ERTHAL ${ }^{1}$ \\ Universidade Federal Fluminense
}

Em seu processo evolutivo, a ciência geográfica privilegiou determinadas temáticas, como o território, paisagem, região, espaço que passaram a constituir suas categorias fundamentais e cada qual dominante num dado período histórico. Longe de serem excludentes, elas mantém, entre si, fortes ligações e interpenetrações, muitas vezes dificultando sua separação, mesmo a nível didático. Deste modo, o conceito de território, por exemplo, se encontra contido ou subjacente ao de região, como o conceito desta em relação à paisagem e, assim, por diante.

Cada uma destas categorias, por seu turno, registra significativo avanço conceitual. A título de exemplo, o espaço era concebido por I. Kant "como a condição de possibilidade dos fenômenos", recorda Santos (1980: 31/32). A esta concepção de espaço tridimensional como continente (receptáculo) que, inclusive foi incorporada ao pensamento hartshorniano, agregou-se aquela do espaço como reflexo da fenomenologia social. Ambas visões, porém, destituíram o espaço do atributo de dinamicidade. $\mathrm{Na}$ nova geografia, além de ser concebido como relativo, "o espaço aparece pela primeira vez na história do pensamento geográfico, como o conceito-chave da disciplina", afirma Corrêa (1995: 20). Com o advento da chamada geografia crítica, observam-se grandes avanços no entendimento formal do espaço, considerado como produto (histórico e dialético) e fator sociais, como nos apresenta Santos (1980).

Assim, as diferentes acepções de cada uma dessas categorias são fruto de diversos paradigmas que vêm estruturando a geografia e que, por sua vez, encontram-se

\footnotetext{
'Professor do Departamento de Geografia da UFF.
} 
articuladas às diversas correntes filosóficas, fornecedoras de critérios epistemológicos e às relações da geografia com as disciplinas afins. $\mathrm{O}$ desenvolvimento teóricometodológico que se observa na geografia, na prática, muito se deve à ação dos seus diferentes ramos (urbana, regional, econômica etc.) que, por especificidade, entram mais freqüentemente em contato com as ciências afins e, como capilares, trazem seivas nutritivas ao corpo teórico geográfico, oxigenando e renovando-o.

Se a geografia se coloca como um campo de conhecimento preocupado com a dimensão espacial da sociedade, não se pode esquecer que ós fenômenos sociais são, também, temporais. Tempo e espaço, fenômenos inter-relacionados e que ocorrem de modo simultâneo, são tomados pela filosofia e pela ciência como categorias universais e históricas, respectivamente. Portanto, estas categorias não são prisioneiras desta ou daquela ciência e podem, conseqüentemente, ser apreendidas por todas. Desse modo, no entender de Abreu (2000: 15) as distinções entre a geografia e as ciências sociais são "exatamente as questões que (a geografia) coloca para o entendimento desse real da sociedade. E essas questões não podem ser apenas as do presente".

Neste sentido, papel fundamental deve ser dado à chamada geografia histórica que, inclusive, além de se preocupar em recuperar as espacialidades pretéritas que marcam as espacialidades atuais, busca metodologias apropriadas e esforça-se em refletir a categoria tempo, a fim de fornecer subsídios à abordagem espacial e temporal. O próprio Carl Ritter já recomendava, em termos metodológicos, uma extensa pesquisa bibliográfica do passado a fim de melhor entender a região.

Embora pouco difundida e, até mesmo em certos momentos, marginalizada pelos próprios geógrafos, a geografia histórica, em seu trajeto de construção, foi tida como disciplina autônoma, como apêndice da história e, também, como campo da antropologia. Os seus praticantes, porém, foram direcionando, por compatibilização, tal saber ao campo geográfico.

Nos países desenvolvidos como Inglaterra, França, Estados Unidos, Canadá, Japão e Austrália, a geografia histórica conseguiu se impor pela qualidade de seus quadros e pela produção empírica e teórica, chegando a construir centros de excelência, a exemplo da Universidade de Wiscousin ${ }^{2}$. No Brasil, este ramo geográfico não conseguiu estabelecer uma tradição que se consubstanciasse numa escola. A produção tradicional ficou praticamente no passado, principalmente até a II Guerra ${ }^{3}$. Após uma lacuna temporal, ressalta-se, em tempo mais recente, a importante contribuição de Maurício de Almeida Abreu e de Pedro Vasconcelos. O primeiro direciona suas pesquisas à cidade do Rio de Janeiro, enquanto, o segundo, a Salvador.

\footnotetext{
${ }^{2}$ Meinig afirma que intensas discussões sobre a natureza da geografia histórica foram empreendidas nos anos de 1950 e 1960, destacando-se neste aspecto a Universidade de Wiscousin. D. W. Meining. 1989.

Entre as instituiçōes que se destacaram na produção da geografia histórica destacam-se a Sociedade Brasileira de Geografia, o Instituto de Geografia e História Militar do Brasil e o Instituto Brasileiro de Geografia e Estatística. Entre os nomes mais notáveis salientam-se: Afonso Várzea, Cristóvão Leite de Castro, José Veríssimo da Costa. Jurandir Pires Ferreira. Alberto Ribeiro Lamego. Fora do âmbito geográfico. Alberto Torres e Oliveira Viana, ideólogos na área de Direito, também podem ser registrados.
} 
A geografia histórica, muitas vezes, tem sido confundida com história da geografia e, em função de falta de uma definição mais precisa, apresenta uma imensa gama de definições como geografia do passado, paisagem em mudança, o passado no presente.

Wooldridge e Gordon East (1967: 18) generalizaram muito o campo da geografia histórica ao afirmarem que ela "tem como tarefa a reconstrução das geografias do passado". Na mesma linha de pensamento posiciona-se Broeck (1981: 45) ao dizer que "A geografia histórica propriamente dita trata especificamente do passado geográfico”. Um pouco mais explícitos se colocam Hugo e Hebert Hassinger (1952: 18) ao definirem tal objeto como a reconstrução das "paisagens culturais de tempos passados e explicar sua gestação à base das circunstâncias culturais e políticas". Aliás, é importante frisar que a geografia histórica, tradicionalmente, esteve muito ligada ao estudo da paisagem.

\section{Um esforço de periodização}

Todo e qualquer esforço para distinguir as fases evolutivas da geografia histórica torna-se árduo e, nem sempre, com resultados satisfatórios. Grosso modo, a evolução da geografia histórica acompanhou a própria evolução da geografia (tradicional, nova e crítica) e Butlin periodizou-a em três fases e as denominou de clássica, neoclássica e social.

\section{Fase Clássica}

Na tradição clássica, a geografia histórica, de base positivista e empírica, ocupou lugar saliente no contexto geográfico de certos países, onde se destacaram temáticas como povoamento e fronteiras numa perspectiva da paisagem e da região, exprimindo-se freqüentemente com a linguagem cartográfica. Acredita Butlin (1987: 21) que ela apresentava "um forte compromisso com estudo histórico da paisagem e pelo mapeamento dos dados dos recursos históricos, ...”. Neste período, a geografia histórica entronizou-se como crédito acadêmico num momento em que se observava um forte repúdio ao determinismo geográfico. Os importantes pontos de referência da tradição ocidental da geografia histórica foram os Estados Unidos, Inglaterra e

\footnotetext{
${ }^{4} \mathrm{H}$. Barrows, a partir da Universidade de Chicago no início do século XX. lançou os fundamentos daquela que se constituiria na tradicional escola americana. De visảo ambientalista e conservacionista, Barrows referenciou-se nos estudos das relações entre o homem e o meio natural e concebia a geografia como uma ecologia humana. Embora de início influenciado por Ellen Semple (geógrafa) e Frederich Turner (historiador), Barrows repudiou a escola determinista. No começo, sua obra de caráter monográfico assentou-se na fisiografia mas, na década de 1920, talvez em função das críticas metodológicas de Walter Tower que considerava a geografia histórica "como a aplicação da geografia econômica do passado", Barrows aderiu tal a concepção, conforme salienta W. A. Koelsk (1969: 638).
} 
França. Nos Estados Unidos, as bases da geografia histórica podem ser atribuídas, entre outros, a H. Barrows ${ }^{4}$, R. Hartshorne, C. Sauer e na Inglaterra a H. C. Darby.

Expoente da geografia norte-americana que, inclusive, debateu questões epistemológicas substanciais relacionadas à geografia histórica, foi Hartshorne. Em sua obra The nature of geography (1939), baseou-se o geógrafo no filósofo I. Kant ao procurar um lugar para a geografia no espectro das ciências. Ele interpretou a visão kantiana em que caberia a história narrar os fenômenos através do tempo, enquanto à geografia caberia descrevê-los no espaço. Como situar, então, a geografia histórica em tal contexto? A única porta de entrada deste campo seria através do famoso método denominado corte-transversal, pois se trata do estudo do espaço num dado momento de tempo, num tempo cristalizado, isto é, a descrição do presente histórico de uma área ou região e não uma narrativa temporal. Os próprios geógrafos historiadores, à época, não aceitavam integralmente a posição hartshorniana. Mas, em sua Perspectiva on the nature of geography (1959), a rigidez de Hartshorne é, parcialmente, quebrada ao admitir estudos de processo em determinado aspecto, quando afetando o entendimento da área.

Não se pode omitir o papel desempenhado por um dos mais conceituados geógrafos americanos - Carl Sauer - que reconheceu a importância da geografia histórica para o desenvolvimento da geografia. Sauer Identificou-se com a geografia vidalina ao conceber a geografia como o estudo da paisagem humanizada, a paișagem cultural. Mas como entender as paisagens presentes sem ter ciência de sua gênese e evolução? Ao contrário de Hartshorne, estava ele preocupado com os processos de mudança. Para Sauer, "a geografia histórica era em essência a análise de processos geográficos”, remarca Guelke (1982: 9).

$\mathrm{Na}$ Inglaterra, este ramo da geografia, em sua fase clássica centrou-se, principalmente, na figura de Darby que conseguiu, nas décadas de 1920 e 1930, aglutinar, a seu redor, um grupo de especialistas. A preocupação maior desses geógrafos era de ordem metodológica que, inclusive, obtiveram sucesso através de novas abordagens e técnicas, já o mesmo não se deu com a teoria.

No dizer de Butlin, o principal achado de Darby foi o conhecimento experimental e pragmático. Ele valorizou, apesar de algumas dificuldades práticas, o método corte-transversal sucessivo, pois salientava a importância dos processos de mudança, afirmando que "a paisagem que vemos não é um arranjo estático de objetos", como realça Guelke (1982: 10).

Darby identificou-se com Hartshorne em relação à natureza da geografia e com Sauer quanto à necessidade de se investigar os processos. No entanto, entendia 0 geógrafo inglês que a geografia destes dois americanos carecia de uma abordagem histórica. Neste sentido estava ele aberto às críticas e indagava se seria possível

\footnotetext{
${ }^{5} \mathrm{Na}$ coletânea Land and life, a selection from the writing of Carl Ortwon Sauer, encontra-se preciosa contribuição de Sauer sobre a questão.
} 
desenhar uma linha divisória entre a geografia e a história. No seu entender, isto era impossível, chegando mesmo a afirmar que "toda a geografia é geografia histórica, atual ou potencial", conforme Guelke (1982: 10). No entanto, a concepção de Darby sobre a história, também, não era rica, pois achava que todos os eventos do passado eram, naturalmente, históricos. Por outro lado, não distinguiu ele os passados natural e humano e, neste sentido, não desenvolveu um método específico para o entendimento dos processos afeitos à ação humana.

$\mathrm{O}$ avanço do método corte-transversal sucessivo deveu-se ao japonês K. Fujiota, ao combiná-lo ao método narrativo. Foi o chamado método corte transversal denso que permitiu incorporar, segundo Kinda (1997: 64), "uma maior cadeia de evidências (do arqueólogo ao contemporâneo) no estudo de mudança regional no tempo".

$\mathrm{Na}$ França, a geografia histórica não teve dificuldade em se colocar dada a importância do papel da história nos tradicionais estudos da paisagem e da região desenvolvidos na geografia clássica francesa. Entre os mais famosos destacam-se C. Valloux e R. Dion.

\section{Fase Neoclássica}

A nova geografia, uma vez implantada, abriu poucas possibilidades à geografia histórica que foi sendo tangida a posições excêntricas. Apesar disto, muitos geógrafos históricos conseguiram aproximar-se do imenso arsenal técnico emanado da matemática e da estatística, a exemplo da análise de regressão, e utilizar-se de uma das maiores invenções tecnológicas - o computador. Este permitiu, de certo modo, avaliar as fontes e armazenar milhares de dados brutos e/ou processá-los.

Progressos também foram sentidos na análise de sistemas, embora a Teoria Geral dos Sistemas não tenha sido muito utilizada na geografia histórica. Esforços foram empreendidos na tentativa de aplicar uma variada gama de modelos matemáticos às tradicionais teorias como as dos grafos, das localidades centrais, regra ordem $\mathrm{x}$ tamanho e locacional, sendo que, em algumas das tentativas, êxitos foram obtidos. Sobre as dificuldades de uso de modelos e técnicas estatísticas na análise geográfica, aponta Butlin (1987: 26) que "o maior problema é que muito das técnicas e modelos utilizados diz respeito à posição de equilíbrio estático e não às mudanças dinâmicas complexas".

Passada a nova geografia, deixando saldos positivos e negativos, merecendo ela um inventário crítico mais profundo, a geografia afastou-se do (neo)positivismo, inclusive, com críticas advindas dos geógrafos históricos.

\section{Fase Social}

Na geografia nova, emergente ao iniciar a década de 1970, não se edificou um só paradigma "oficial" estruturando a ciência geográfica. É certo que a corrente mar- 
xista, com sua postura crítica, exerceu papel fundamental na denúncia e desmonte da nova geografia, mas ela não obteve monopólio do saber e fazer geográficos.

Esta corrente que examina a sociedade através dos materialismos histórico e dialético, tem alcançado êxito ao ser aplicada à geografia. Ela fornece conceitoschaves como o modo de produção (conceito central), relações de produção, mais valia, formação socioeconômica que são ferramentas importantes à compreensão da espacialidade social. $\mathrm{O}$ espaço é visto como uma entidade flexível, manipulada e produzida à imagem do sistema produtivo. A aplicação de tais conceitos pela geografia histórica, certamente, auxiliaria a esclarecer a produção do espaço em diversas escalas. Poder-se-ia entender, por exemplo, a evolução do capitalismo através de sucessivas configurações espaciais que foram se forjando em conseqüência das relações estabelecidas entre a sociedade e a natureza. É fundamental para a afirmação da geografia histórica que ela ultrapassasse as fronteiras do lugar e da região par alcançar escalas mais abrangentes. Na apreciação de Butlin (1987), a produção na geografia histórica de cunho marxista era numericamente pouco expressiva.

Convivem com a geografia marxista as perspectivas idealista, estruturalista, humanística e têmporo-espacial. Enfim, observa-se uma pluralidade de posturas, mas que convergem para uma preocupação comum de caráter teórico-metodológico.

A abordagem idealista foi introduzida na geografia por L. Guelke com a publicação do The idealist geography em 1974. As idéias desta escola assentam-se no pensamento contido na obra (Idea of history -1946) do filósofo e historiador R. G. Collingwood. Esta geografia, segundo Christofoletti (1982: 24), "representa tendência para valorizar a compreensão das ações envolvidas nos fenômenos, procurando focalizar o seu aspecto interior, que é o pensamento subjacente às atividades humanas". Collingwood considerava que uma dada ação humana compreende dois aspectos - interior e exterior. O exterior, nas palavras de Christofoletti, "compreende todos os aspectos de uma ação passíveis de descrição em função de corpos e de seus movimentos, enquanto a parte interior das ações é o pensamento subjacente aos seus aspectos observáveis (p. 25). Assim, o idealismo passou a ser uma alternativa ao positivismo, considerando-se a dimensão do comportamento humano. O geógrafo idealista tem como meta compreender a evolução da paisagem cultural ao trazer à luz o pensamento que se encontra atrás dela. Neste caso, as teorias derivam das próprias ações humanas e é objetivo vital ao idealista prover um relato e sua explicação. Em consequiência de tal postura, a geografia idealista conforma-se dentro de tradições idiográficas. Esta abordagem geográfica, no entanto, não tem encontrado suporte para o seu desenvolvimento, comenta Butlin.

O incentivo ao estruturalismo na geografia partiu de D. Gregory que, por sua vez, encontrava-se filiado às idéias do sociólogo A. Giddens. Esta corrente filosófica pretende entender as transformações que ocorrem na sociedade, a partir da ação e reação dialética entre as experiências de indivíduos/grupos de indivíduos e as estruturas sociais. Na obra de Gregory, observa-se o renascimento da narrativa. Mas "en- 
quanto o uso da narrativa para apreender do lugar não é genericamente difícil, sua habilidade para verificar a estrutura espacial é problemática e isto é central para a estruturação teórica", conclui Butlin (1987: 32).

É notório um maior interesse pela geografia histórica, principalmente, com a chegada da corrente humanista. Isto se deve, segundo Butlin, ao aguçamento da sensibilidade da geografia humana e à aproximação e diálogo da geografia com as ciências sociais. Na década de 1970, a geografia histórica torna-se mais internalizada e institucionalizada no seio geográfico. Tal ascensão traduz-se pelo nascimento e expansão de grupos de pesquisa, tanto a nível local quanto internacional, pela criação e circulação de periódicos especializados como pela própria realização de congressos internacionais patrocinados pela UGI.

Sem dúvida, a corrente humanística foi uma das mais promissoras perspectivas que chegaram à geografia. O humanismo contemporâneo inspira-se na fenomenologia de E. Husserl e contribuições vitais de Heidegger, Merleau-Ponty e Sartre. Na geografia destacam-se as obra de Yi-Fi Tuan, A. Buttimer e E. Relph entre outros.

Com a geografia humanística , abriram-se novos horizontes em termos conceituais (espaço, território, lugar, paisagem etc.) de método (compreensão) e temáticas (comunidade, segregação étnica, cidadania, movimentos sociais, regionalismo, cultura popular, saúde , prostituição, drogas etc.).

A fenomenologia, segundo Christofoletti (1982: 22), "preocupa-se em analisar os aspectos essenciais dos objetos da consciência, através da supressão de todos os preconceitos que um indivíduo possa ter sobre a natureza dos objetos, como os provenientes das perspectivas científica, naturalista e do senso comum".

A geografia humanística interessa-se por valores, significações, sentimentos, símbolos, intuição, propósitos (subjetividades) dos indivíduos, grupos e comunidades e suas relações com o lugar onde vivem. Neste contexto, a noção de espaço toma novos contornos conceituais, passando a ser concebido como presente, vivido, como sendo de certa espessura. Tal espessura, acrescenta Christofoletti (1982: 22), "é vista na concepção do "aqui", que é um sistema de relações com outros lugares, semelhante à espessura dos conceitos temporais, tais como "agora", que envolve aspectos do passado, presente e futuro".

Nesta abordagem, espaço e tempo tomam novas dimensões. Assim, "a percepção visual, o tato, o movimento e pensamento se combinam para dar-nos o nosso sentido característico de espaço, possibilitando a capacidade para reconhecer e estruturar a disposição dos objetos” (p. 23), conclui Christofoletti. Uma vez que o espaço é deste modo percebido, o lugar, conseqüentemente, fica em evidência. O lugar não se confunde mais com qualquer localidade, ele passa a ter significado afetivo para as pessoas, grupos e comunidades. A distância volta-se ao âmbito espaço-temporal, pois envolve noções de perto e longe, de passado, presente e futuro. Não se pode esquecer, neste quadro de referência, a importância que toma o ambiente natural e cultural que vitaliza os estudos geográficos ligados à primeira natureza, ecologia, paisagem e região. 
Já a geografia têmporo-espacial, na visão de Christofolleti (1982: 29), "procura analisar as atividades dos indivíduos e das sociedades em função das variáveis tempo e espaço, visando traçar as trajetórias dos ritmos de vida (diários, anuais e da própria duração da vida) assinalando a alocação de tempo desprendido nas diversas atividades e vários lugares".

\section{A questão do tempo}

Naturalmente, além do espaço, a questão do tempo reveste-se de crucial importância nos estudos de geografia histórica. Na geografia histórica clássica aceitou-se a idéia temporal da história. Como dito, na visão hartshorniana, o tempo não era de vital importância à geografia, fato rechaçado pelo seu contemporâneo Sauer que via no tempo um processo. Enfim, a concepção de tempo, pouco discutida na geografia, encontrava-se defasada com novos conceitos produzidos por diversas ciências.

Até 1915, em função da concepção física newtoniana, tempo e espaço eram considerados como um palco sobre o qual eventos ocorriam, inclusive socioeconômicos. Com a teoria geral da relatividade de Einstein, que revolucionou a física clássica, mudou-se esta visão. O movimento dos corpos alterava a estrutura tempo-espaço e vice-versa. Na atualidade, o desenvolvimento tecnológico vem transformando, rapidamente, tais relações, através do avanço nos transportes e comunicação, esta via "superhighway" - união da telemática com as telecomunicações ${ }^{6}$.

$\mathrm{Na}$ relação entre a geografia histórica e a categoria tempo, levantam-se questões como: tempo como um problema teórico e metodológico, dimensão tempo-espaço, periodicidade e difusão espacial.

Avanço significativo no tocante à gênese dos fenômenos e às formas espaciais na construção da teoria e na metodologia sobre o tempo, o tempo-geográfico foi alcançado por T. Häggerstrand ${ }^{7}$. A teoria desenvolvida pelo geógrafo sueco ${ }^{8}$, agregada ao esquema de notação, permite interações entre trajetórias de sendas de vidas individuais em diferentes escalas: individual, de situação ou lugar (por exemplo, lugares de trabalho) e sistema populacional ou de atividades.

Em relação à produção de Häggerstrand, Santos (1997) observa que apesar dos progressos alcançados, ficaram problemas pendentes em função da ausência de um conceito de tempo social e de um método capaz de dar conta de questões do tempo e

\footnotetext{
${ }_{7}^{6}$ Alcoforado, F. - "Espaço-tempo e desenvolvimento". 03/10/1997.

7 O tempo geográfico inclui o "estudo da análise do curso de vida em diferentes escalas e envolvendo o mapeamento das trajetórias individuais, comumente, por meio de um sistema demográfico de notação conhecido como diagrama de Lexis-Becker ou mapas diagramáticos dinâmicos, com o movimento dos indivíduos plotados num eixo vertical de tempo e, numa segunda dimensão, no eixo horizontal de espaço". Butlin (1993: 60).

${ }^{8}$ Sobre a teoria da difusão espacial de inovações, ver Silva, C. A. F. da . - Os avatares da teoria da difusão espacial: uma revisão teórica. 1995.
} 
do espaço. Sobre esta importante questão do tempo-geográfico, Butlin ${ }^{9}$ traz a polêmica estabelecida entre Pred e Thrift, por um lado, e Baker, por outro.

A fim de penetrar no mundo das relações tempo e espaço, Santos (1980: 205) considera as idéias de A. Whitehead de que as relações entre eventos são, simultaneamente, espaciais e temporais e quando se pensa neles, separadamente, passa-se ao mundo da abstração. Desse modo, completa Santos, "tudo o que existe articula o presente ao passado, pelo fato de sua própria existência (...). Desse modo, um enfoque espacial isolado ou um enfoque temporal isolado são ambós insuficientes. Para compreender uma qualquer situação, necessitamos de um enfoque espaço-temporal".

Em uma de suas últimas obras, Santos (1997: 44) aborda a questão acima colocada e traz importantes contribuições a nível conceitual e de método. Acentua o autor a preocupação de se obter a unificação do tempo e do espaço, numa perspectiva epistemológica totalizadora. Para isto, há necessidade de definir estas duas categorias em termos operacionais, materializá-las a fim de serem, mutuamente, includentes e conversíveis. A resolução de tal equação é encontrada por Santos, via técnica. As técnicas permitem, por um lado, "a possibilidade de empirização do tempo e por outro a possibilidade de uma qualificação precisa da materialidade sobre a qual as sociedades humanas trabalham". E, ao longo do desenvolvimento histórico, as técnicas vão se caracterizando de forma diferenciada. Eis o tempo empirizado. Desta forma, "é por intermédio das técnicas que o homem, no trabalho, realiza essa união entre espaço e tempo", conclui o autor.

\section{A atenção ao método}

Para que os espaços pretéritos sejam intelectualmente reproduzidos e, desse modo, inteligíveis, a geografia histórica necessita desenvolver um método de análise adequado ao seu campo de estudo e, neste sentido, importante contribuição traz Abreu (2000: 18). É fundamental não se esquecer que, os espaços socialmente construídos, desde os primórdios, são bastante diferentes no ecúmeno, além de cada civilização ou grupos evoluírem com ritmos bastante diferenciados entre si e no seu próprio processo de mudanças.

\footnotetext{
'Como objetivo de exemplificar a tempo geográfico, A. Pred estudou o tempo na produção, o tempo familiar e tempo livre nas cidades norte-americanas no século XIX. Ele demonstrou que a nascente atividade industrial, por exemplo, desfez a autodeterminação do uso do tempo, impondo mudanças no uso de tempo da produção, familiar e de lazer. Baker, entre outros, criticou o conceito de tempo-espaço na obra de Pred, afirmando haver uma excessiva ênfase a essas categorias e que elas não são a única preocupação dos geógrafos. Acrescenta, ainda, que os trabalhos realizados nessa linha dão demasiada atenção à descrição e não ao processo. Por outro lado, Baker afirma que períodos e lugares são mais significativos para os geógrafos históricos do que os conceitos gerais de tempo e espaço. Pred e Thrift responderam a essa crítica, tentando demonstrar, nas palavras de Butlin (1993: 60), que "o tempo-geográfico tem maior flexibilidade em relação ao entendimento do processo e que o seu uso é compatível com a máxima da ideologia humanista e antes que uma tentativa de prover uma teoria geral de estruturas, tenta prover a teoria da estruturação".
} 
Para o autor, o método constitui-se na única diferença em termos de estudo do presente e do passado, na medida em que as categorias analíticas forem verdadeiramente universais. Acrescenta, ainda, que a categoria presente pode e deve ser utilizada para a orientação do método do estudo do passado, pois "são as ações que transcorrem no presente que redefinem as heranças do passado e preparam o futuro".

Naturalmente, a evolução cultural da humanidade se encontra muito articulada ao desenvolvimento das técnicas aplicadas em vários setores no processo de relação do ser social com a natureza. Assim, estudando os espaços pretéritos, do ponto de vista geográfico, há que se respeitar algumas regras metodológicas e, entre elas, aponta Abreu:

- embora as categorias geográficas sejam universais, as variáveis que tornam possíveis operacioná-las, não o são. Elas têm que ser adequadas ao contexto do passado em exame;

- o "presente de então" só pode ser compreendido à medida de sua contextualização;

- há que se investir em levantamento bibliográfico referente ao tempo que se queira estudar (pesquisa indireta) e realizar incursões em instituições que guardam a memória dos acontecimentos (pesquisa direta).

Frisa-se que o pesquisador que trabalha com informações registradas no passado mais remoto, pode enfrentar um grande obstáculo em relação à forma de apresentação dos documentos, mesmo no vernáculo. Muitas vezes, elas só podem ser corretamente decifradas através do auxílio da filologia. No Brasil, se, por um lado, tal problema não se apresenta de modo tão crucial, pois nossos registros mais antigos remontam ao século XVI, por outro, nossa grande barreira fica por conta da manutenção e conservação documental.

\section{GEOGRAFIA HISTÓRICA - CONSIDERAÇÕES}

Resumo: A Geografia Histórica é uma parte da Geografia que sempre esteve presente na história e interpretações dos espaços desta ciência. Às vezes colocada no esquecimento, às vezes voltando a ocupar um lugar de grande importância, a Geografia Histórica cumpre um papel fundamental no desenvolvimento da teoria e do método, sobretudo no atual momento.

Palavras-chave: Geografia Histórica, Teoria, Método

\section{HISTORICAL GEOGRAPHY - CONSIDERATIONS.}

Abstract: Historical Geography is a part of Geography that has always been present in history and interpretations about spaces on this science. Has sometimes been forgotten and returns other times to occupy a great important place. Historical Geography has a fundamental paper about development of theory and method, specially at current moment.

Key words: Historical Geography; theory; method.

\section{BIBLIOGRAFIA}

- ABREU, M. de A.- 2000. Construindo uma geografia do passado: Rio de Janeiro, cidade portuária, século XVII. GEOUSP, Espaço e Tempo, Departamento de Geogreafia. USP, SP, 13 - 25. 
- ALCOFORADO, F. - 1997. Espaço-tempo e desenvolvimento. Folha de São Paulo, SP, 03/10.

- BROEK, J. O. M. - 1981. Iniciação ao estudo de geografia. Biblioteca de Ciências Sociais. Zahar Editores, $4^{\circ}$.edição, RJ, 155 p.

- BUTLIN, R. A. - 1993. Historical geography in the second half of the twentieth century. In: Historical geography - througt the gates of space and time. Edward Arnold, London, New York, Melbourne, Auckland, 44 - $72 .$.

- 1987 Theory and methodology in historical geography. In: Historical geography: progress and prospect. Edited by M. Pacione. London, Walfeboro, New Hampshire, 16 - 45.

- CORRÊA, R. L. - 1995. Espaço: um conceito-chave da geografia. In: Geografia, coneitos e temas. Org. Castro, I. E. et alii. Editora Bertrand Brasil S. A., RJ, 15 47.

- GUELKE, I. - 1982 Conceitos inadequados da história em geografia histórica. In: Historical understandig in geography - an idealist approach. Cambridge University Press. Cambridge, London, New York, New Rochelle, Melbourne, Sidney. 5 - 24.

- HASSINGER, H. e Hassinger, H. - 1952 Geografia e História In: Fundamentos geográficos da história. Viena, 13 - 22.

- PACIONI, M (coletor). Historical geography: progress and prospect.1987. London, Walfebors, New Hampshire, 306 p.

- KINDA, A. - 1997 Some traditions and methodologies of japonese historical geography. Journal of historical geography, vol. 23, no. 1, January, 62 - 75.

- KOELSCH, W. A. - 1969. The historical geography of Larlaw H. Barrows. AAAG, vol. 59, no. 4, december, 632 - 651 .

- MEINIG, D. W. - 1989 The historical geography imperative. AAG, vol. 79, no. 1, march, 79 - 87.

- SANTOS, M. - 1997 A natureza do espaço. Editora Hucitec, $2^{\text {a }}$. edição, SP, 308 p. - 1980 A noção de tempo nos estudos geográficos. In: Por uma geografia nova. Editora Hucitec, SP, $2^{\circ}$. edição, 203 - 212.

- WEIMIN, Q. - 1995 Historical geography in China. Journal of historical geography, vol. 21 , no. 4 , octobre, 361-370.

- WITHERS, C. W. J. - 1995 How Scotland came to know itself: geography, national identity and the making of a nation, 1680 - 1790. Journal of historical geography, vol. 21 , no. 4 , octobre, 371 - 397.

- WOOLDRIDGE, S. W. e Gordon East, E. W. - 1967 Espírito e propósitos da geografia. Coleção - A terra e o homem. Zahar Editores. RJ, 189 p. 